\title{
Improving Screening Methods to Water Stress in Common Bean (Phaseolus vulgaris L) Using New Score Indices Based on Productivity and Resilience
}

\author{
Parvaze Ahmad Sofi ${ }^{1 *}$, Khalid Rehman', Asmat Ara ${ }^{1}$, S.A. Mir ${ }^{2}$ and S.A. Dar ${ }^{3}$ \\ ${ }^{1}$ Division of Genetics and Plant Breeding, Faculty of Agriculture, SKUAST-Kashmir, India \\ ${ }^{2}$ Division of Agri. Statistics, SKUAST-Kashmir, Shalimar, India \\ ${ }^{3}$ Dry Land Agricultural Research Station, SKUAST-Kashmir, India \\ *Corresponding author email id:
}

\begin{tabular}{|c|c|}
\hline & A B S T R A C T \\
\hline & Here we report the usefulness of a new method for evaluation of a core set of \\
\hline Keywords & $\begin{array}{l}\text { common bean genotypes in terms of a new index based on a combination of stress } \\
\text { susceptibility index, the stress tolerance index, the mean production index, the }\end{array}$ \\
\hline $\begin{array}{l}\text { Common bean, } \\
\text { Water stress, } \\
\text { Stress indices, } \\
\text { Resilience, } \\
\text { Productivity. }\end{array}$ & $\begin{array}{l}\text { geometric mean production index, and the tolerance index, which have been } \\
\text { previously used either in isolation or together for understanding water stress } \\
\text { adaptation. The method is based on a scoring scale, offers simple and easy } \\
\text { visualization and identification of resilient, productive and/or contrasting }\end{array}$ \\
\hline Article Info & genotypes based on grain yield. This new selection method could help breeders \\
\hline $\begin{array}{l}\text { Accepted: } \\
\text { 14 June } 2017 \\
\text { Available Online: } \\
\text { 10 July } 2017\end{array}$ & $\begin{array}{l}\text { in terms of grain yield production under stress. The approach is highly useful in } \\
\text { initial evaluation of large germplasm sets for identification of resilient and } \\
\text { productive genotypes. }\end{array}$ \\
\hline
\end{tabular}

\section{Introduction}

Abiotic stresses (such as drought and high temperature) are reported to cause greater yield reductions, given that they are widespread, often intense and occur almost every year (Wortmann et al., 1998). The importance of abiotic stress is all the more important in low input agricultural systems of underdeveloped countries (Beebe et al., 2010). Drought stress is a worldwide production constraint of common bean (Teran and Singh, 2002). Prolonged drought either as early season, or intermittent or terminal drought, which are generally enhanced by heat and low air relative moisture, are the most damaging for bean and cause an increased frequency of barren plants and incomplete seed setting. Water stress during the flowering and grain filling periods are reported to reduce the seed yield and seed weight and accelerate maturity of dry bean (Singh, 1995). Common bean is not noted for its drought tolerance, yet recent studies suggest that only $7 \%$ of the growing area receives adequate rainfall and $60 \%$ of the production occurs under severe drought stress (White and Singh, 1991). Even in Brazil 
where large-scale agriculture has been widely promoted, only about $4 \%$ of the area and $15 \%$ of the bean production is derived from high input irrigated systems (Broughton et al., 2003). Around $73 \%$ of the total Latin American and $40 \%$ of the total African bean production occurs under micro-climates that have moderate to severe mean water-deficits at some time during the cropping season (van Schoonhoven and Voysest, 1989). Water requirements for maximum production of a 60-120 day bean crop vary from 300 to 500 $\mathrm{mm}$ depending on its environment and nutrition (Allen et al., 1998).

The development of bean genotypes that are more resistant to water stress is a practical and economical approach to lessen the negative effects of drought on the productivity of the crop. There is no clear definition, into the literature, to explain what is considered as drought tolerant genotype. Some define it as the ability of plants to grow and reproduce satisfactorily to produce harvestable yield with limited water supply or when under periodic water deficit (Turner, 1979; Fleury et al., 2010), others have suggested that wheat yield stability is a better indicator of genotypic drought resistance compared with grain yield under stress (Blum et al., 1989). In terms of physiological mechanism, drought resistance is often considered as a compromise between 'dehydration avoidance' and 'dehydration tolerance', both of which can have variable impacts on yield (Fischer and Maurer, 1978; Turner, 1979, 1986; Levitt, 1980). The efforts to understand differential genotypic response under stress in terms of their yield levels per se has not yielded fruitful results and the progress has not been encouraging as yield is a highly complex trait (Sinclair, 2011). Moreover, the extreme level of drought stress could reduce seed yields to very low levels such that genotypic differences disappear, whereas insufficient stress could result in selection of non-resistant genotypes (Beebe et al., 2013). Selection based solely on yield under extreme stress is a poor estimate of drought resistance, since resistance to severe stress may be associated with reduced yield in non-stress environments (Rosielle and Hamblin, 1981). However, we cannot think of any screening protocol without yield as one of the components of the selection index as it is the outcome of all adaptive mechanisms that plants put in place in response to stressful environments.

Since drought resistance is a yield based trait, selection could vary depending on which index is chosen by the breeder. Where differential yield reduction (Yp-Yd) due to stress has been used as a basis for selecting cultivars with resistance to water stress, the strategy can be counterproductive because of the likelihood of selecting low yielding cultivars with a small yield differential. No significant correlation between yield reduction and Yd was observed suggesting that differential yield reduction is not a useful predictor of drought resistance in common bean (Samper, 1984). Breeders have found it very useful to interpret differential yielding abilities in terms of various indices calculated from seed yield. A large number of such indices have been proposed and used by wheat breeders to discriminate the plant response such as stress susceptibility index (SSI), tolerance index (TOL), geometric mean (GM), harmonic mean (HM), mean productivity (MP), geometric mean productivity (GMP), stress tolerance index (STI), relative drought index (RDI), coefficient of drought resistance (CDR), yield stability index (YSI), Abiotic tolerance index (ATI) and many more (Fisher and Maurer, 1978; Fischer et al., 1979; Rosielle and Hamblin, 1981; Bouslama and Schapaugh, 1984; Fernandez, 1992; Moosavi et al., 2008; Chakherchaman et al., 2009; Thiry et al., 2016). In common bean also various studies have reported use of different indices for screening. Ramirez-Vallejo and Kelly (1998) 
used geometric mean (GM) and stress susceptibility index (SSI) to evaluate the association of specific phenological and physiological traits with resistance to drought in common bean. The GM and the stress susceptibility index (SSI) have been used widely for the determination of genotypic differences under drought stress in common bean (Ramirez-Vallejo and Kelly, 1998). Teran and Singh (2002) used geometric mean (GM), percent reduction (PR) and stress susceptibility index (SSI) for yield estimates of drought resistance. Genotypic differences in both GM and SSI have been demonstrated in common bean (Acosta-Gallegos, 1988; Acosta Gallegos and Adams, 1991; Mkandawire, 1987; Schneider et al., 1997; White and Singh, 1991).

A major drawback of using these indices has been lack of correspondence in rankings across indices and their failure to discriminate overlapping responses in terms of yield under stress. Moreover, there have been contrasting reports about their discriminatory powers in identifying optimally yielding genotypes (Ramirez-Vallejo and Kelly, 1998, Khodarahmpour et al., 2011; Mohammadi et al., 2011; Sareen et al., 2012). The differential rankings of genotypes through different indices, across all crops, suggest that the indices per se are potential indicators of different biological responses to drought. Although all these indices are mathematical derivations of the same yield data, selection based on a combination of different indices may provide a more useful criterion for improving water stress adaptation of common bean. However, There are not yet any accurate screening index that can be used in breeding programmes to select genotypes for abiotic stress adaptation and high yield in both stress and non-stress environments. The original indices (as outlined by Fisher and Maurer, 1978; Rosielle and Hamblin, 1981 and Fernandez, 1992) suffer from few basic shortcomings as outlined by Fernandez
(1992) and Thiry et al., (2016) that warrant use of new indices to have a reliable estimation of differential genotypic response under stress environments.

Fernandez (1992) and Thiry et al., (2016) grouped the genotypic response under stress and non-stress conditions into four broad classes (A, B, C and D). The class A represents those genotypes that express uniform superiority in both stress and nonstress condition; the class B genotypes that express good performance only in non-stress and not under stress conditions; the class $\mathrm{C}$ genotypes that exhibit higher yield only under stress; and the class D genotypes that express poor yield performance in both environments. The genotypic responses can seldom be represented as extremes of tolerance and susceptibility and invariably falls in any of these four classes. It seems practically viable to use a combination of different indices to have a much better picture by taking into account different discriminatory powers of indices; nevertheless, as pointed out by Thiry et al., (2016), it is not yet clear how to combine stress indices appropriately. Very recently, Thiry et al., (2016) suggested a new way of combining indices in terms of their abilities to classify genotypes into susceptible and tolerant. The method so devised focuses on resilience and productivity and uses index scores to build the regression equations for elucidating genotypic response. They could combine the five indices into two groups namely class 1 and class 2 ; class 1 discriminates the tolerant from the susceptible, and class 2 distinguishes the tolerant with high mean yield. They could experimentally establish the comparative advantage of combining index scores to develop two new indices RCI (based on index scores of SSI and TOL) and PCI (based on index scores of MP, GMP and STI) in a core set of 294 wheat genotypes over the indices per se. The objective of the present study was to have a reliable screening index based on 
resource remobilisation and to test the applicability of newly developed score indices (Thiry et al., 2016) in common bean, in order to elucidate the characteristics of the best performing and adapted genotypes under stress and to further establish the usefulness of such combined index in crop breeding programmes aimed at identifying common bean genotypes resilient to water stress.

\section{Materials and Methods}

\section{Plant materials}

Twenty genotypes of common bean were evaluated in the present study. The genotypes used were selected from a core germplasm set on the basis of their performance in the yield screening trials and represented diverse market classes in terms of use category, growth habits and seed characteristics. The material comprised of 17 breeding lines and three released varieties namely SR-1, SFB-1 and Arka Anoop. While the SR-1 and SFB-1 have been released by SKUAST-Kashmir, Arka Anoop has been released by IIHR, Bengaluru. Out of 20 genotypes, 14 were bush determinate and six were indeterminate pole type. The genotypes were screened at all the three levels (laboratory, green house and field) for root architecture, biomass partitioning and various physiological parameters (data not presented here).

\section{Field experiment}

Genotypes were grown in the research field of Faculty of Agriculture, Wadura, Sopore $\left(34^{\circ}\right.$ $17^{\prime} \mathrm{N}$ and $74^{\circ} 33^{\prime} \mathrm{E}$ at an altitude of $1524 \mathrm{~m}$ amsl). The soil of the experimental site is a typical inceptisol with clay loam texture with adequate nutrient supply. The $\mathrm{pH}$ is almost neutral (7.2), with organic carbon $0.65 \%$, electrical conductivity of 0.18 deci-siemens $/ \mathrm{m}$ and CEC of $16 \mathrm{meq} / \mathrm{kg}$. The mean temperature $\left({ }^{\circ} \mathrm{C}\right)$ and relative humidity $(\%)$ during the experimental period was 26.99
(Min. 18.71 and Max. 30.43) and 82.07 (Min. 73.26 and Max. 87.67) respectively and the total rainfall during the period was $13.12 \mathrm{~mm}$. Each genotype was grown as a single row of four meter length, with spacing of $15 \mathrm{~cm}$ x 40 $\mathrm{cm}$, with two replications each for water stress and irrigated treatments. Plants were irrigated regularly until the first fully opened trifoliate leaf and irrigation was withdrawn thereafter in stress treatment whereas the plants in irrigated treatment were watered regularly. Plots were protected from rain with mobile shelters with transparent polyethylene on top and sides. The non-stress rows were maintained at $100 \%$ field capacity by irrigation with water from sowing to final harvest. For the water stress treatment, plants were stressed by withholding water from trifoliate stage to pod development stage. The duration of drought stress was $60 \mathrm{~d}$. During the drought stress period, all genotypes showed leaf rolling symptom. The moisture content of soil in water stress treatment at end of the stress treatment was 30\%, which was quantified using a soil moisture probe. Data was recorded for seed yield under both water regimes (water stress and well watered).

\section{Drought tolerance indices}

Seed yield was calculated as the mean of all the plants across replications. Various drought tolerance indices were calculated based on the values of seed yield per plant under irrigated and drought conditions to discriminate genotypes on the basis of drought response in terms of grain yield. The calculations were done as follows:

Stress susceptibility index $(\mathrm{SSI})=\left\{1-\left(\mathrm{Y}_{\mathrm{S}} /\right.\right.$ $\left.\left.\mathrm{Y}_{\mathrm{NS}}\right)\right\} /\left\{1-\left(\mathrm{X}_{\mathrm{S}} / \mathrm{X}_{\mathrm{NS}}\right\}\right.$ (Fisher and Maurer, 1978)

Tolerance index $(\mathrm{TOL})=\mathrm{Y}_{\mathrm{NS}}-\mathrm{Y}_{\mathrm{S}}($ Rosielle and Hamblin, 1981)

Mean productivity $(\mathrm{MP})=\left(\mathrm{Y}_{\mathrm{S}}-\mathrm{Y}_{\mathrm{NS}}\right) / 2$ (Rosielle and Hamblin, 1981) 
Geometric mean productivity $(\mathrm{GMP})=\sqrt{ }($ $\mathrm{Y}_{\mathrm{NS}} \mathrm{X} \mathrm{Y}_{\mathrm{S}}$ ) (Fernandez, 1992)

Stress Tolerance Index $\left.(\mathrm{STI})=\mathrm{Y}_{\mathrm{S}} \mathrm{x} \mathrm{Y}_{\mathrm{NS}}\right) /$ $\mathrm{X}_{\text {NS }}^{2}$ (Fernandez, 1992)

Where $Y_{S}$ and $Y_{N S}$ are mean yields of genotypes under stress and non-stress conditions respectively and $\mathrm{X}_{\mathrm{S}}$ and $\mathrm{X}_{\mathrm{NS}}$ are mean of yield of all genotypes under stress and non-stress conditions.

\section{New screening indices}

In order to overcome the ambiguity regarding the reliable genotypic response to stress conditions using the yield per se and the five stress indices (SSI, TOL, MP, GMP and STI), two new indices defined as resilience and production capacity indices (Thiry et al., 2016) were used. Thiry et al., (2016) outlined the discriminatory power of the resilience capacity index (RCI) in terms of the yield decrease of the genotypes under stress within a population, compared with yield potential (non-stress) conditions; and the production capacity index (PCI) in terms of the mean production of the genotypes under both stressed and non-stressed conditions within a population. They emphasised that the combined use of the five indices (SSI, TOL, MP, GMP and STI), and both new indices (RCI and PCI) are highly effective in understanding the basis of any yield limitations under stress.

Thiry et al., (2016) divided these five indices into two classes viz., Class 1 (SSI and TOL) and Class 2 (MP, GMP and STI) based on the premise that the first class tends to identify genotypes based on resilience and productivity respectively. They proposed two new indices that combine the discriminatory power of the score indices. These score indices have been classified within two new scales called resilience capacity index (RCI) and production capacity index (PCI). The scoring scale for each index is based on deriving the range from minimum and maximum values from original index.. This range is further divided into ten parts and each part has a score from 1 to 10 in a way that each part represents $10 \%, 20 \%$, or $100 \%$ of the range value. Additionally, the value of TOL and SSI are inverted, so a high value obtained with the original equation will receive a lower score in all case that allows the two classes of indices to have the same scale, where a high score will always mean a 'good' genotype and a lower score a poor genotype (Thiry et al., 2016). The index scores can then are easily combined and test them against yield under stress and non-stress conditions to elucidate differential genotypic response in terms of adaptability stress and/ or non-stress environments.

\section{Results and Discussion}

\section{Drought tolerance indices}

In the first instance, we used five indices namely SSI, TOL, MP, GMP and STI for understanding genotypic response under moisture stress (Table 1). All the indices showed variable rankings that further substantiate the need to develop a more relevant index. However, the rankings of MP and GMP were invariably similar. On the basis of mean rankings of all indices, WB1634, WB-341, SFB-1 and WB-451 were identified as desirable genotypes with fair amount of yield stability under water stress and WB-6, WB-1587, WB-1492 and WB-112 were the genotypes with lowest rankings. The rank 5, 7 and 11 were shared by two genotypes each (WB-956 and SFB-1; WB185 and WB-1446; and WB-83 and Arka Anoop respectively). The sharing of ranks due to overlaps in a small set of 20 genotypes implicates a potential problem with large germplasm sets in terms of large number of overlaps. The correlation between the overall 
rank and the individual ranks of indices was highest for STI (0.848) followed by GMP (0.836), SSI (0.821), MP (0.801) and lowest for TOL (0.388). Porch (2006) used GM, heat susceptibility index (STI in present case), heat tolerance index (STI in present case) to screen for heat tolerance in common bean and reported that the GM and HTI proved to be the most useful indices for the evaluation of genotypic performance under heat stress and they were highly correlated. HTI, GM and HSI were all correlated with yield under heat stress, whereas HTI and GM were more highly correlated with yield under low-stress conditions. Similarly, high correlation between low yield potential and low SSI scores has been reported in drought stress in bean (White and Singh, 1991). However, in both these and other reported cases, these indices have been used separately to rank the genotypes for relative tolerance to stress environments. However, it has been suggested that a combination of stress indices (tolerance and susceptibility indices) might provide a more useful criterion for improving drought stress tolerance selection in common bean and heat stress tolerance selection in maize (Thiry et al., 2016).

\section{Comparative analysis of original indices and index scores}

In this study first tested the score indices against their original value from each index (Table 3). The Pearson correlation coefficient between the score indices and the original indices calculated on yield data from the 20 genotypes evaluated under drought and irrigated conditions. The correlation coefficient between the score stress susceptibility index (SSIs) and the score tolerance index (TOLs) values and their original index values (SSI and TOL) is highly negative (ranging from -0.801 to -0.993 ), as the score scale has been inverted in order to create a scale showing resilience instead of susceptibility. On the other hand, the Pearson correlation coefficients between the original values for MP, GMP and STI and the score indices MPs, GMPs and STIs are highly significant. These high Pearson correlation coefficient values demonstrate that the score indices can be used as a surrogate of their original index value as suggested by Thiry et al., (2016).

In order to identify the best combination of indices we performed the linear regression and the coefficient of determination of the different score indices v/s yield under nonstress and heat stress environments, calculated on 20 genotypes (Figure 1) which clearly indicated that no index, used individually, could clearly identify the high yielding genotypes, independently of the environment. This observation conforms to the result reported by Khayatnezhad et al., (2010) and Thiry et al., (2016) from a study with 22 and 294 genotypes of wheat respectively. In each class of index (susceptibility and tolerance), SSI and STI showed the closest relationship (Figure 2) with yield under water stress ( $R=$ 0.383 and 0.938 respectively). In contrast, TOL and MP show a close relationship with yield potential (non-stress) environment ( $\mathrm{R}=0.208$ and 0.924 respectively). These results are same as reported by Thiry et al., (2016). The results of the present study substantiate the premise that the combination of the score indices from each class would improve the relationship between the indices per se and grain yield. The two new indices (RCI and PCI) as proposed by Thiry et al., (2016) are based on the combination of score indices. They outlined the effectiveness of the new indices based on datasets from 10 wheat genotypes and suggested that the new indices can be used for evaluation of germplasm sets of any scale. The score indices are presented in table 2 using grain yield data of 20 genotypes. The $\mathrm{Y}_{\mathrm{NS}}$ and $\mathrm{Y}_{\mathrm{S}}$ data refer to yield levels achieved by genotypes in productive and stressful environments, considering that the $\mathrm{Y}_{\mathrm{NS}}$ represents the maximum grain yield 
that a genotype is able to produce under favourable environments. Table 3 indicates also the correlation between the indices within each class of indices in the 20 genotypes. The most important observation from the correlation of index scores and original indices, in the present study as well as the one reported by Thiry et al., (2016), is that within each class the values are almost same. Therefore, these score values (Table 2) and the Pearson correlation coefficient (Table 2) substantiate the premise that SSI and TOL can be associated to class 1 and, MP, GMP and STI, can be associated to class 2. These two classes were used to build two new indices that would represent two different characteristics of plant response viz., resilience capacity and production capacity, respectively.

In terms of class 1 (SSI and TOL) index scores, WB -1634, SFB-1, WB-1643 and WB-341 turn out as better and WB-22, WB1492 , and WB-6 are poor. Similarly in terms of class 2 (MP, GMP and TOL) index scores, WB-1634, WB-341 and WB-451 are better genotypes while WB-1587, WB-6, AA, WB216 and SR-1 turn out to be poor genotypes. When evaluated in terms of RCI and PCI, The genotypes WB-1634, WB-341 and WB-1643 seem to posses better resilience (higher RCI values) as compared to poor ones such as WB-6, WB-22, WB-1492. Similarly, in terms of PCI, the genotypes WB-1634, WB-341 and WB-1643 again show better productive potential (higher PCI values) as compared to WB-6, SR-1, AA, and WB-401. Combined into YSSI (yield stress score index) and YPSI (yield potential score index), we could identify WB-1634, WB-341 and WB-1643 as having better resilience and WB-1634, WB341 and WB-451 as having better productivity. These differentiations that become obvious using these new indices could be very useful for a crop breeding programme aimed at identification of highly resilient and productive genotypes or only highly resilient ones for crossing with highly productive genotypes. Contrasting genotypes in terms of resilience or productivity could provide an understanding of the possible role of morphological, biochemical and physiological adjustments that a genotype puts in place under stress and non-stress environments. The ability of certain genotypes to exhibit higher yield under stress can be derived from a genotype that is either tolerant or has a good yield performance under non-stress or a combination of both and may be a result of various underlying processes that can be elaborated by using various biochemical, physiological and biomass partitioning traits. Thiry et al., (2016) in their study outlined the fact that genotypes belonging to different groups may have comparable per se yields under stress but may have different yields under potential nonstress conditions. However, such genotypes may undergo smaller reductions in yield under stress resulting in higher resilience, which can be identified by a higher RCI value. Therefore, the score indices can be effectively used for understanding differential genotypic plasticity to stress in terms of RCI and PCI values rather than per se yield values. Table 3 shows the data on seed yield of 20 common bean genotypes. We can see some peculiar genotypic scores in terms of RCI and PCI. The genotypes WB-22 and WB-1492 had exactly similar values of YSSI (2.0) and YPSI (3.00) indicating that these genotypes had similar capacities of productivity and resilience. Similarly, the genotypes WB-956 and WB-1446 share the similar relationship. On the contrary, WB-451 and WB-1643 having comparable values of YSSI but almost opposite values of YPSI. Similarly, WB-185 and SFB-1 despite having similar values of YSSI had almost opposite values of YPSI indicating that in such instances, genotypes differed in their productive and resilience capacities. 
Table.1 Yield under stress and non-stress and five indices in 20 common bean genotypes

\begin{tabular}{|c|c|c|c|c|c|c|c|c|c|c|c|c|c|}
\hline Genotype & $\begin{array}{l}\text { Yield } \\
\text { (NS) }\end{array}$ & Yield (S) & SSI & Rank & TOL & Rank & MP & Rank & GMP & Rank & STI & Rank & $\begin{array}{c}\text { Mean } \\
\text { rank }\end{array}$ \\
\hline WB-6 & 19.55 & 8.78 & 1.75 & 20 & 10.77 & 16 & 14.16 & 18 & 13.10 & 19 & 0.27 & 19 & 17 \\
\hline WB-22 & 29.32 & 14.35 & 1.62 & 18 & 14.97 & 20 & 21.83 & 8 & 20.51 & 9 & 0.67 & 10 & 12 \\
\hline WB-83 & 24.67 & 16.33 & 1.07 & 14 & 8.34 & 13 & 20.50 & 12 & 20.07 & 11 & 0.64 & 12 & 11 \\
\hline WB-112 & 26.06 & 14.97 & 1.35 & 17 & 11.09 & 17 & 20.51 & 11 & 19.75 & 12 & 0.62 & 13 & 14 \\
\hline WB-185 & 34.44 & 21.74 & 1.17 & 15 & 12.7 & 18 & 28.09 & 4 & 27.36 & 4 & 1.19 & 4 & 7 \\
\hline WB-216 & 16.28 & 12.17 & 0.80 & 6 & 4.11 & 4 & 14.22 & 14 & 14.07 & 16 & 0.32 & 17 & 9 \\
\hline WB-222 & 31.1 & 21.23 & 1.01 & 11 & 9.87 & 14 & 26.16 & 5 & 25.69 & 5 & 1.05 & 5 & 6 \\
\hline WB-257 & 25.38 & 17.41 & 1.01 & 12 & 7.97 & 12 & 21.39 & 10 & 21.02 & 8 & 0.70 & 9 & 8 \\
\hline WB-341 & 33.18 & 27.24 & 0.57 & 3 & 5.94 & 8 & 30.21 & 2 & 30.06 & 2 & 1.44 & 2 & 2 \\
\hline WB-401 & 15.10 & 11.68 & 0.72 & 5 & 3.42 & 1 & 13.39 & 19 & 13.28 & 18 & 0.28 & 18 & 10 \\
\hline WB-451 & 33.72 & 23.17 & 0.99 & 10 & 10.55 & 15 & 28.44 & 3 & 27.95 & 3 & 1.24 & 3 & 4 \\
\hline WB-956 & 25.41 & 18.61 & 0.85 & 7 & 6.80 & 10 & 22.01 & 7 & 21.74 & 7 & 0.75 & 7 & 5 \\
\hline WB-1446 & 24.96 & 17.84 & 0.91 & 8 & 7.12 & 11 & 21.40 & 9 & 21.10 & 9 & 0.71 & 8 & 7 \\
\hline WB-1492 & 27.35 & 13.16 & 1.65 & 19 & 14.19 & 19 & 20.25 & 14 & 18.97 & 13 & 0.57 & 14 & 15 \\
\hline WB-1587 & 13.5 & 8.26 & 1.23 & 16 & 5.24 & 7 & 10.88 & 20 & 10.55 & 20 & 0.18 & 20 & 16 \\
\hline WB-1634 & 36.05 & 31.96 & 0.36 & 1 & 4.09 & 3 & 34.00 & 1 & 33.94 & 1 & 1.83 & 1 & 1 \\
\hline WB-1643 & 25.52 & 20.69 & 0.60 & 4 & 4.83 & 5 & 23.10 & 6 & 22.97 & 6 & 0.84 & 6 & 3 \\
\hline SR1 & 20.18 & 13.43 & 1.06 & 13 & 6.75 & 9 & 16.80 & 15 & 16.46 & 14 & 0.43 & 15 & 13 \\
\hline SFB-1 & 22.11 & 18.57 & 0.51 & 2 & 3.54 & 2 & 20.34 & 13 & 20.26 & 10 & 0.65 & 11 & 5 \\
\hline $\mathrm{AA}$ & 17.69 & 12.50 & 0.93 & 9 & 5.19 & 6 & 15.09 & 16 & 14.87 & 15 & 0.35 & 16 & 11 \\
\hline
\end{tabular}


Table.2 Score indices based on grain yield for five tolerance indices (SSI. TOL, MP, GMP, STI) in 20 common bean genotypes

\begin{tabular}{|c|c|c|c|c|c|c|c|c|c|}
\hline \multirow[b]{2}{*}{ Genotypes } & \multicolumn{2}{|c|}{ Seed yield (g) } & \multicolumn{2}{|c|}{ Class 1} & \multicolumn{3}{|c|}{ Class 2} & \multirow{2}{*}{$\begin{array}{l}\text { Mean score } \\
\text { index }\end{array}$} & \multirow{2}{*}{$\begin{array}{c}\text { Mean } \\
\text { genotypic } \\
\text { Rank }\end{array}$} \\
\hline & Stress & $\begin{array}{l}\text { Non- } \\
\text { stress }\end{array}$ & SSI score & TOL score & MP Score & GMP Score & STI Score & & \\
\hline WB-6 & 19.55 & 8.78 & 1 & 4 & 2 & 2 & 1 & 2.0 & 19 \\
\hline WB-22 & 29.32 & 14.35 & 1 & 1 & 5 & 5 & 3 & 3.0 & 17 \\
\hline WB-83 & 24.67 & 16.33 & 5 & 6 & 5 & 5 & 3 & 4.8 & 11 \\
\hline WB-112 & 26.06 & 14.97 & 3 & 4 & 5 & 4 & 3 & 3.8 & 15 \\
\hline WB-185 & 34.44 & 21.74 & 5 & 2 & 8 & 8 & 7 & 6.0 & 7 \\
\hline WB-216 & 16.28 & 12.17 & 7 & 10 & 2 & 2 & 1 & 4.4 & 13 \\
\hline WB-222 & 31.1 & 21.23 & 6 & 5 & 7 & 7 & 6 & 6.2 & 6 \\
\hline WB-257 & 25.38 & 17.41 & 6 & 7 & 5 & 5 & 4 & 5.4 & 10 \\
\hline WB-341 & 33.18 & 27.24 & 9 & 8 & 9 & 9 & 8 & 8.6 & 2 \\
\hline WB-401 & 15.10 & 11.68 & 8 & 10 & 2 & 2 & 1 & 4.6 & 12 \\
\hline WB-451 & 33.72 & 23.17 & 6 & 4 & 8 & 8 & 7 & 6.6 & 4 \\
\hline WB-956 & 25.41 & 18.61 & 7 & 8 & 5 & 5 & 4 & 5.8 & 8 \\
\hline WB-1446 & 24.96 & 17.84 & 7 & 7 & 5 & 5 & 4 & 5.6 & 9 \\
\hline WB-1492 & 27.35 & 13.16 & 1 & 1 & 5 & 4 & 3 & 2.8 & 18 \\
\hline WB-1587 & 13.5 & 8.26 & 4 & 9 & 1 & 1 & 1 & 3.2 & 16 \\
\hline WB-1634 & 36.05 & 31.96 & 10 & 10 & 10 & 10 & 10 & 10.0 & 1 \\
\hline WB-1643 & 25.52 & 20.69 & 9 & 9 & 6 & 6 & 5 & 7.0 & 3 \\
\hline SR-1 & 20.18 & 13.43 & 5 & 8 & 3 & 3 & 2 & 4.2 & 14 \\
\hline SFB-1 & 22.11 & 18.57 & 9 & 10 & 5 & 5 & 3 & 6.4 & 5 \\
\hline $\mathrm{AA}$ & 17.69 & 12.50 & 6 & 9 & 2 & 2 & 2 & 4.2 & 14 \\
\hline
\end{tabular}


Table.3 Pearson correlation coefficient between the score indices (SSIs, TOLs, MPs, GMPs and STIs) and their original indices (SSI, TOL, MP, GMP and STI)

\begin{tabular}{llllll}
\hline TRAIT & SSI & TOL & MP & GMP & STI \\
\hline Class 1 & & & & & \\
SSIs & $-0.993^{*}$ & $-0.805^{*}$ & 0.374 & 0.430 & 0.458 \\
TOLs & $-0.801^{*}$ & $-0.994^{*}$ & -0.207 & -0.148 & -0.082 \\
Class 2 & & & & & \\
MPs & -0.357 & 0.197 & $0.995^{*}$ & $0.992^{*}$ & $0.974^{*}$ \\
GMPs & -0.408 & 0.140 & $0.992^{*}$ & $0.994^{*}$ & $0.981^{*}$ \\
STIs & -0.442 & 0.068 & $0.975^{*}$ & $0.981^{*}$ & $0.992^{*}$ \\
\hline
\end{tabular}

Table.4 Values of RCI and PCI and their combination into YSSI and YPSI

\begin{tabular}{|c|c|c|c|c|}
\hline GENOTYPE & RCI & PCI & YSSI & YPSI \\
\hline WB-6 & 1 & 1 & 1.00 & -1.00 \\
\hline WB-22 & 1 & 3 & 2.00 & 3.00 \\
\hline WB-83 & 5 & 3 & 4.00 & -1.50 \\
\hline WB-112 & 3 & 3 & 3.00 & 0.50 \\
\hline WB-185 & 5 & 7 & 6.00 & 4.00 \\
\hline WB-216 & 7 & 1 & 4.00 & -7.00 \\
\hline WB-222 & 6 & 6 & 6.00 & 1.00 \\
\hline WB-257 & 6 & 4 & 5.00 & -2.00 \\
\hline WB-341 & 9 & 8 & 8.50 & 0.00 \\
\hline WB-401 & 8 & 1 & 4.50 & -7.50 \\
\hline WB-451 & 6 & 7 & 6.50 & 2.50 \\
\hline WB-956 & 7 & 4 & 5.50 & -3.00 \\
\hline WB-1446 & 7 & 4 & 5.50 & -2.50 \\
\hline WB-1492 & 1 & 3 & 2.00 & 3.00 \\
\hline WB-1587 & 4 & 1 & 2.50 & -5.50 \\
\hline WB-1634 & 10 & 10 & 10.00 & 0.00 \\
\hline WB-1643 & 9 & 5 & 7.00 & -3.50 \\
\hline SR-1 & 5 & 2 & 3.50 & -4.00 \\
\hline SFB-1 & 9 & 3 & 6.00 & -5.50 \\
\hline $\mathrm{AA}$ & 6 & 2 & 4.00 & -5.50 \\
\hline
\end{tabular}


Fig.1 Linear regression and coefficient of determination (R2) between yield under stress and YSSI and yield under non-stress and YPSI

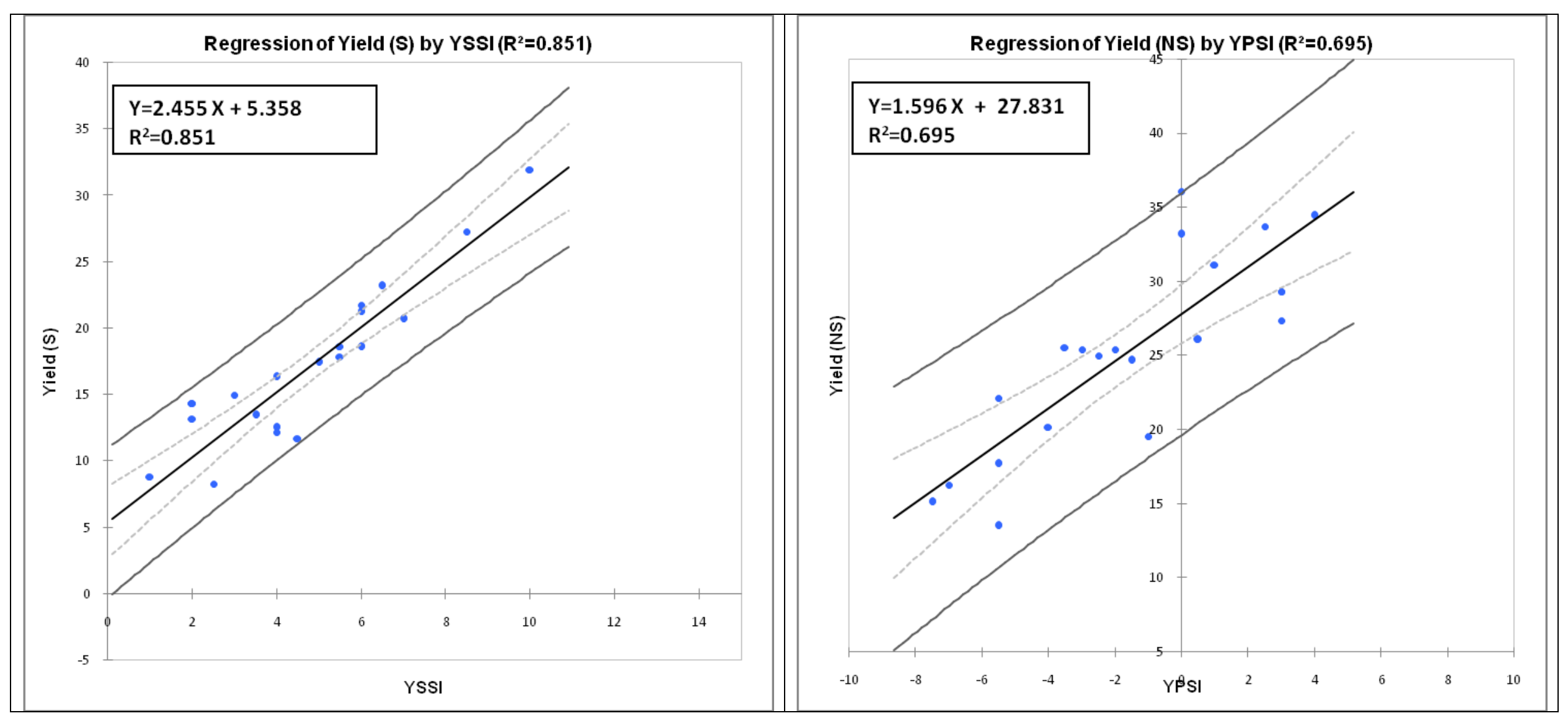


Fig.2 Linear regression and coefficient of determination (R2) between yields under stress and non-stress and score indices

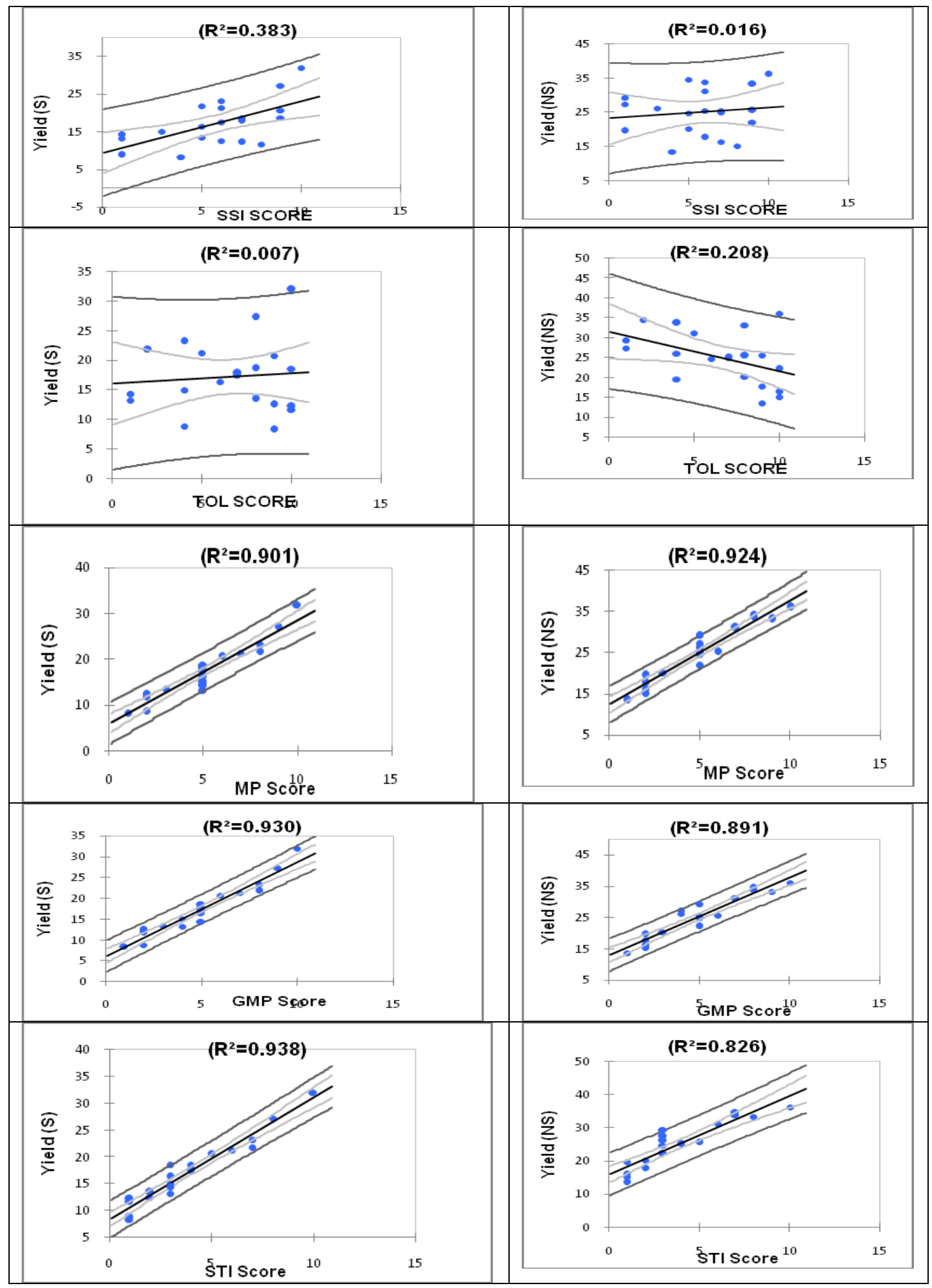


In order to develop a potential array of genotypes that could have high yield potential as well as climate resilience it would be advisable to select and cross the parents with high level of resilience and productivity. In our study we could identify a potential combination of WB-1634 and WB-341 as having highest degrees of productivity and resilience. They are both indeterminate pole types, have almost comparable phenology and can be used as parents in crossing programme. As suggested by Thiry et al., (2016), while selecting parents on the basis of RCI and PCI values, the phenology of genotypes should be given due consideration as the stage of stress may vary depending upon the phenology of the crop. It would be highly worthwhile to integrate phenology to the proposed the index or analyse the population separately for the early, mid and late genotypes. The more uniform the population is, in terms of phenology, the better the index will perform in identifying contrasting genotypes or genotypes with high yield performance, as one of the bases of the score index method is to compare the genotypes' response within the whole population.

In conclusion, the present paper reports the evaluation of a set of 20 common bean genotypes for water stress adaptation in terms a set of new indices based on index scores that define genotyping response in terms of resilience and productivity. We conclude that the new indices originally proposed and used in wheat (Thiry et al., 2016) were found to be highly efficient to elucidate genotypic response to water stress in terms of resilience and productivity and overcomes the obvious limitations of using various indices including the ones used in the present study in isolation as it results in inconsistencies in rankings of genotypes. The present method is a useful approach of combining the indices into a well defined index that differentiates the genotypes on the basis of resilience and productivity. The results reported in the present study and the earlier one reported in wheat can be effectively used to screen any set of genotypes with equal efficiency.

\section{Acknowledgement}

The authors are highly thankful to Arnauld Thiry, Lancaster Environment Center, Lancaster University UK for critically reviewing the manuscript.

\section{Declaration}

The author declares no conflict of interest.

\section{References}

Acosta-Gallegos, J.A. 1988. Selection of common bean (Phaseolus vulgaris L.) genotypes with enhanced drought tolerance and biological nitrogen fixation. Ph D diss. Michigan State Univ East Lansing (Diss Abstr 88-24816).

Acosta-Gallegos, J.A. and Adams, M.W. 1991. Plant traits and yield stability of dry bean (Phaseolus vulgaris) cultivars under drought stress. J. Agric. Sci., (Cambridge) 117: 213-219.

Allen, R.G., Pereira, L.S. and Raes, D. 1998. Crop evapo-transpiration-guidelines for computing crop water requirements. FAO Irrigation and drainage paper, 56: FAO, Rome, Italy.)

Beebe, S.E., Rao, I.M., Blair, M.W. and Acosta-Gallegos, J.A. 2013. Phenotyping common beans for adaptation to drought. Frontiers Physiol., 4: 1-20.

Blum, A., Shipiler, L., Golan, G. and Mayer, J. 1989. Yield stability and canopy temperature of wheat genotypes under drought stress. Field Crops Res., 22: 289-296.

Bouslama, M., Schapaugh, W.T. 1984. Stress 
tolerance in soybean. Part 1: Evaluation of three screening techniques for heat and drought tolerance. Crop Sci., 24: 933-937.

Broughton, W., Hernández, G., Blair, M., Beebe, S., Gepts, P. and Vanderleyden, J. 2000. Beans (Phaseolus spp.) model food legumes. Plant and Soil, 252: 55-128.

Cuellar-Ortiz, S., Arrieta-Montiel, M., Acosta-Gallegos, J.A. and Covarrubias, A. 2008. Relationship between carbohydrate partitioning and drought resistance in common bean. Plant Cell Env., 31: 1399-1409.

Chakherchaman, S.A., Mostafaei, H., Imanparast, L. and Eivazian, M.R. 2009. Evaluation of drought tolerance in lentil advanced genotypes in Ardabil region. Iran J. Food Agric. Env., 7(3-4): 283-288.

Fernandez, G.C. 1992. Effective selection criteria for assessing plant stress tolerance, p. 257-27 In: Proceeding of a symposium on adaptation of vegetables and other food crops in temperature and water stress, Taiwan.

Fischer, R.A., Maurer, R. 1978. Drought resistance in spring wheat cultivars. I. Grain yield responses. Crop and Pasture Sci., 29: 897-912.

Fleury, D., Jefferies, S., Kuchel, H., Langridge, P. 2010. Genetic and genomic tools to improve drought tolerance in wheat. J. Experimental Botany, 61: 3211-3222.

Hall, A.E. 1993. Is dehydration tolerance relevant to genotypic differences in leaf senescence and crop adaptation to dry environments? In: T.J. Close and E.A. Bray. Eds.), Plant Responses to Cellular Dehydration During Environmental Stress, pp. 1-10. The American Soc. Plant Pathologists, Rockville, Maryland.

Khayatnezehad, M. and Gholamin, R. 2010. Investigation and selection drought stress indexes for corn. AmericanEurasian J Agriculture and Env. Sci., 9: 22-26.

Khodarahmpour, Z., Choukan, R., Bihamta, M.R., Hervan, E.M. 2011. Determination of the best heat stress tolerance indices in maize. Zea mays $\mathrm{L}$. inbred lines and hybrids under Khuzestan Province conditions. J. Agri. Sci. Technol., 13: 111-121.

Mkandawire, A.B.C. 1987. Productivity of Malawian landrace dry beans under intercropping and drought conditions. $\mathrm{Ph} \mathrm{D}$ diss Michigan State Univ East Lansing. Diss Abst., 88-07094.

Mohammadi, M., Karimizadeh, R., Abdipour, M. 2011. Evaluation of drought tolerance in bread wheat genotypes under dryland and supplemental irrigation conditions. Australian J. Crop Sci., 5: 487-493.

Moosavi, S., Yazdi Samdi, B., Naghavi, M., Zali, A., Dashti, H. and Pourshabazi, A. 2008. Introduction of new indices to identify relative drought tolerant and resistant genotypes of wheat. Desert, 12: $165-178$

Porch, T.G. 2006. Application of stress indices for heat tolerance screening of common bean. J. Agron. Crop Sci., 192: 390-394. doi:10.1111/j.1439037X.2006.00229.X

Ramırez, P. and Kelly, J.D. 1998. Traits related to drought resistance in common bean. Euphytica, 99: 127-136.

Rosales, M., Ocampo, E., Olvera-Carillo, D., Acosta-Gallegos, J.A. and Covarrubias, A. 2012. Physiological analysis of common bean. Phaseolus vulgaris L.. cultivars uncovers characteristics related to terminal drought resistance. Plant Physiol., 56: 24-34

Rosielle, A.A., Hamblin, J. 1981. Theoretical aspects of selection for yield in stress and non-stress environments. Crop Sci., 21: 943-946. 
Samper, C. 1984. Effect of water stress imposed at mid-pod filling upon yield and dry matter partitioning in dry beans. Phaseolus vulgaris L.. MS Thesis Michigan State Univ East Lansing. Diss Abstr., 13-25000.

Sareen, S., Tyagi, B.S., Sharma, I. 2012. Response estimation of wheat synthetic lines to terminal heat stress using stress indices. J. Agri. Sci., doi: http://dx.doi.org/10.5539/jas.v4n10p97.

Schneider, K.A., Rosales-Serna, F., IbarraPerez, B., Cazares-Enriquez, J., AcostaGallego, J.A., Ramirez-Vallejo, N., Wassimi, N. and Kelly, J.D. 1997. Improving common bean performance under drought stress. Crop Sci., 37: 4350.

Sinclair, T.R. 2011. Challenges in breeding for yield increase for drought. Trends Plant Sci., 16: 289- 293

Singh, S.P. 1995. Selection for water stress tolerance in interracial populations of common bean. Crop Sci., 35: 118-124.

Teran, H., Singh, S.P. 2002. Comparison of sources and lines selected for drought resistance in common bean. Crop Sci., 42: 64-70.

Thiry, A., Perla, N., Chavez, D., Reynolds, M.P. and Davies, W.J. 2016. How can we improve crop genotypes to increase stress resilience and productivity in a future climate? A new crop screening method based on productivity and resistance to abiotic stress. $J$. Experimental Bot., doi:10.1093/jxb/erw 330

Turner, N.C. 1979. Drought resistance and adaptation to water deficits in crop plants. In: Mussell H, Staples RC, eds. Stress physiology in crop plants. New York: John Wiley and Sons, 343-372

Turner, N.C. 1986. Adaptation to water deficits: a changing perspective. Australian J. Plant Physiol., 13: 175190.

van Schoonhoven, A., and Voysest, O. 1989. Common beans in Latin America and their constraints. In: H.F. Schwartz and M.A. Pastor- Corrales. Eds.), Bean Production Problems in the Tropics, pp. 33-57. CIAT, Colombia.

White, J.W., Singh, S.P. 1991. Breeding for adaptation to drought. In $\mathrm{A}$ van Shoonhoven, O Voysest, eds, Common Beans: Research for crop improvement. CABI, Walingford, and CIAT, Cali. pp 501-560

Wortmann, C.S., Kirkby, R.A., Eledu, C.A., Allen, D.J. 1998. Atlas of common bean. Phaseolus vulgaris L. production in Africa. CIAT publication no. 297. CIAT, Cali, Colombia, $131 \mathrm{pp}$

\section{How to cite this article:}

Parvaze Ahmad Sofi, Khalid Rehman, Asmat Ara, S.A. Mir and S.A. Dar. 2017. Improving Screening Methods to Water Stress in Common Bean (Phaseolus vulgaris L) Using New Score Indices Based on Productivity and Resilience. Int.J.Curr.Microbiol.App.Sci. 6(7): 967-981. doi: https://doi.org/10.20546/ijcmas.2017.607.118 